\title{
Psychopathic Traits of Dutch Adolescents in Residential Care: Identifying Subgroups
}

\author{
Karin S. Nijhof • Ad Vermulst • Ron H. J. Scholte • \\ Coleta van Dam • Jan Willem Veerman • \\ Rutger C. M. E. Engels
}

Published online: 3 September 2010

(C) The Author(s) 2010. This article is published with open access at Springerlink.com

\begin{abstract}
The present study examined whether a sample of $214(52.8 \%$ male, $M$ age $=15.76, S D=1.29)$ institutionalized adolescents could be classified into subgroups based on psychopathic traits. Confirmatory Factor Analyses revealed a relationship between the subscales of the Youth Psychopathic traits Inventory (YPI) and the three latent constructs of the original model on which it is based. Latent Class Analyses showed that adolescents showing psychopathic traits could be classified into three subgroups. The first group showed low scores on the grandiose/manipulative dimension, the callous/ unemotional dimension, and the impulsive/irresponsible dimension (normal group). The second group scored moderate on the grandiose/manipulative dimension and the callous/ unemotional dimension and high on the impulsive/irresponsible dimension (impulsive, non-psychopathic-like group). The third group scored high on all three dimensions (psychopathy-like group). The findings revealed that the impulsive, non-psychopathic like group scored significantly higher on internalizing problem behavior compared to the normal group, while the psychopathy-like and the impulsive, non-psychopathic-like group both scored higher on externalizing problem behavior compared to the normal group. Based on a self-report delinquency measure, it appeared that the psychopathy-like group had the highest delinquency rates, except for vandalism. Both the impulsive and psychopathylike group had the highest scores on the use of soft drugs.
\end{abstract}

K. S. Nijhof $(\bowtie) \cdot$ A. Vermulst $\cdot$ R. H. J. Scholte $\cdot$

J. W. Veerman $\cdot$ R. C. M. E. Engels

Behavioural Science Institute, Radboud University Nijmegen,

P.O. Box 9104, 6500 HE Nijmegen, The Netherlands

e-mail: k.nijhof@bsi.ru.nl

C. van Dam $\cdot$ J. W. Veerman

Praktikon, Nijmegen, The Netherlands
Keywords Adolescents · Residential settings · Psychopathic traits $\cdot$ Problem behavior

\section{Introduction}

In the Netherlands, about 2000 adolescents exhibiting severe behavior problems are treated in compulsory residential youth care. Although officially these adolescents were not admitted because of criminal activities, $70 \%$ had contacts with the police (Nijhof et al. 2010). Generally, psychopathy is found to be more prevalent within adolescents than in childhood (Hare 2003) and we also would expect it to be present in a residential sample. However, the extent of psychopathic traits among adolescents in residential settings is unknown, as studies in these settings are currently lacking. In the present study, we examined whether a residential sample of adolescents can be classified into subgroups based on psychopathic traits and to what extent differences in internalizing behaviors, externalizing behaviors, and drug use characterize these subgroups.

A psychopathic personality involves an arrogant and deceitful interpersonal style, a defective emotional experience (e.g., shallow emotions and a lack of remorse, empathy, and responsibility for one's own actions), and impulsive, irresponsible, and sensation-seeking behavior (Hare 1991). Studies examining psychopathy mostly identify interpersonal, affective and behavioral dimensions of the construct, although some studies also include a fourth antisocial dimension. Like all personality disorders, a psychopathic personality cannot be diagnosed before the age of 18 (American Psychiatric Association 1994); however, individuals can show psychopathic traits before this age. The prevalence rates of psychopathic traits in a 
normal adolescent population were found to range between 5\% and 6\% (Andershed et al. 2002; Gustafson 2000). The prevalence of psychopathy is higher in boys than in girls (e.g., Bolt et al. 2004; Salekin et al. 1998; Sevecke et al. 2009b).

Psychopathic traits seem to be relatively stable over time (Forsman et al. 2008; Loney et al. 2007; Lynam et al. 2007). Genetic and environmental factors were found to be associated with psychopathic traits (Forsman et al. 2008). Larsson et al. (2006) showed that common genetic influences explained between $43 \%$ and $56 \%$ of the variance in the three psychopathic dimensions, which is similar to other studies (Blonigen et al. 2003; Taylor et al. 2003). Larsson et al. (2006) also revealed that non-shared environmental factors could explain $37 \%$ of variance in psychopathic traits, while shared environmental influences did not contribute.

The Youth Psychopathic traits Inventory (YPI; Andershed et al. 2001) and the Psychopathy Checklist: Youth version (PCL: YV; Forth et al. 2003) are widely used instruments to measure psychopathic traits in adolescence. In contrast to the PCL: YV, the YPI does not require rigorous training prior to conducting the assessment (Hillege et al. 2010). Moreover, it was found that self-report measures, such as the YPI, are useful in research on psychopathic traits (Andershed et al. 2002). Studies on the correlations between scores on the YPI and the PCL:YV report low to moderate correlations, suggesting that both instruments measure somewhat different constructs (Andershed et al. 2007; Cauffman et al. 2009; Dolan and Rennie 2006; Skeem and Cauffman 2003).

Although some studies include the antisocial dimension as a fourth dimension, the YPI assesses three dimensions: grandiose/manipulative (interpersonal), callous/unemotional (affective), and impulsive/irresponsible (behavioral) psychopathic personality dimensions (Hare 1991). Using the YPI, Andershed et al. (2001) found that three subgroups of psychopathic adolescents could be identified within a normative sample. The first subgroup scored low on all three aspects, the second group showed average scores on the affective and interpersonal aspect and high scores on the behavioral aspect. The third group scored high on all three aspects. Using the PCL: YV, Andershed et al. (2008) reported similar findings when distinguishing subgroups in a sample of male offenders.

Psychopathic traits, externalizing and internalizing behavior

Most research examining the relationship between psychopathy and externalizing problems includes conduct problems and attention deficit hyperactivity disorder (ADHD) as measures of externalizing problems. Both are found to be strongly related to psychopathic traits (e.g., Johansson et al. 2005; Forth et al. 2003; Sevecke et al. 2009b). More specifically, Abramowitz et al. (2004) found that conduct problems, as well as ADHD, were important predictors of the behavioral dimension of psychopathy in adults. In contrast, for adolescents, Mathias et al. (2007) found that only the behavioral factor, but not the other psychopathy factors, was related to symptoms of ADHD in partial correlation analyses. Colledge and Blair (2001) also found that the impulsivity of ADHD among children was related to the behavioral factor of psychopathy. Sevecke et al. reported that conduct disorder (Sevecke et al. 2009a, b) and ADHD (Sevecke et al. 2009a) contributed to the behavioral dimension of psychopathy in boys. Moreover, conduct disorder was also related to the interpersonal, affective and antisocial dimension (2009a) in boys, while for ADHD these links were not found. In girls, conduct disorder was linked with the affective, behavioral and antisocial factors of psychopathy, while ADHD contributed to all four dimensions of psychopathy (Sevecke et al. 2009a). Sevecke et al. (2009b) also found that externalizing symptoms, measured using the Youth Self Report (YSR), were associated with the affective dimension of psychopathy in girls, whereas antisocial behavior was related to the behavioral and interpersonal dimension. Using a two-factor model, Abramowitz et al. (2004) found that both ADHD and childhood conduct problems were stronger predictors for the antisocial lifestyle factor compared to the interpersonal affective factor. In sum, stronger relations were found between externalizing problems and the behavioral and antisocial factor scores than between externalizing problems and the affective and interpersonal factor scores, although some differences between boys and girls were found.

About $15 \%$ to $20 \%$ of the criminal population is diagnosed as having a psychopathic personality (Hart and Hare 1997). In adolescence, the psychopathy-like group shows the most severe pattern of antisocial behavior compared to other offenders (e.g., Andershed et al. 2002; Lynam and Gudonis 2005). Adolescents with psychopathic traits often engage in delinquent behaviors earlier, show more versatility in offending, commit more violent crimes, and show higher rates of recidivism than other offenders (Lynam and Gudonis 2005; Skeem and Cauffman 2003; Vincent et al. 2003; Walters 2003). Higher scores on psychopathy are related to a higher likelihood of delinquency in both boys and girls (Marsee et al. 2005). Regarding the relationships between the dimensions of psychopathy and delinquent behavior, Christian et al. (1997) found that adolescents scoring high on the affective dimension, who also had childhood conduct disorder, showed a more serious criminal career than adolescents scoring lower on the affective dimension (see also Barry et al. 2000; Loney et al. 2003). More recent studies, however, revealed that recidivism is more strongly related to the behavioral dimension than to the interpersonal and affective dimension (Douglas et al. 2006; 
Edens et al. 2007). Salekin (2008) investigated the association between psychopathy using the PCL:YV and both general as well as violent recidivism. Moderately positive correlations were found between the three dimensions of the factor model of psychopathy and general and violent offending, except for the interpersonal dimension and violent recidivism.

Additionally, drug use is positively related to psychopathic traits (Andershed et al. 2008, Murrie and Cornell 2000; Poythress et al. 2006). Hillege et al. (2010) found that the interpersonal, affective as well as the behavioral dimension were related to drug use. However, for boys the impulsive/irresponsible dimension showed a stronger relationship with drug use than the other two dimensions, and for girls the affective dimension showed a stronger association with drug use. Poythress et al. (2006) found that the behavioral dimension was mainly related to drug use in the past. However, Poythress et al. also found a significant association between drug use and the interpersonal dimension. In sum, psychopathic traits are positively associated with both delinquent behavior and drug use. In addition, the combination of psychopathic traits and drug abuse is associated with higher levels of recidivism (Taylor and Lang 2006). More specifically, prior studies suggest that the behavioral dimension is more strongly related to both drugs use and recidivism than the affective and interpersonal dimensions.

Concerning internalizing problems, Poythress et al. (2006) found a positive direct relation between psychopathic traits and internalizing problems (self-esteem, withdrawal, anxiety, worrisome recurring thoughts, depression, fatigue or loss of interest). Salekin et al. (2004) confirmed this finding. Moreover, several studies investigated anxiety and the link with psychopathy (e.g., Kosson et al. 2002; Kubak and Salekin 2009; Skeem and Cauffman 2003). In general it was found that anxiety was positively related to psychopathic traits in adolescence. In addition, gender differences emerged in the relationship between psychopathic traits and internalizing problems. Sevecke et al. (2009b) found that a significant relationship between internalizing symptoms measured by the Youth Self Report (YSR) and the affective dimension of psychopathy existed only for boys. On the other hand, psychopathic traits are also associated with low levels of internalizing problems (Brandt et al. 1997; Frick et al. 1999; Lynam 1997). The relationship between internalizing behavior and psychopathy might be an indirect one because conduct problems are strongly associated with both psychopathic traits and internalizing problems. Moreover, internalizing problems are common in adolescents diagnosed with conduct problems (Lambert et al. 2001). For example, within clinical samples, between 60 to $75 \%$ of the children with a conduct disorder also showed anxiety disorders (Russo and Beidel 1993). In sum, psychopathic traits are linked to internalizing problems, probably due to direct or indirect associations with conduct problems.

\section{The present study}

The present study will examine whether the three dimensions underlying the ten psychopathic traits of the YPI are present in a clinical adolescent sample referred to residential care. Most studies on psychopathic traits of adolescents included normative samples or samples consisting only of (male) offenders, while our study included males and females from residential settings. The first aim of the study was to test the validity of the YPI in a clinical sample, hypothesising the same factor structure as reported by Andershed et al. (2001). The next aim was to test whether the adolescents could be classified into different subgroups based on psychopathic traits. Further, it was examined whether these subgroups show different levels of problem behavior, delinquent behavior, and substance use. It was hypothesized, based on the study of Andershed et al. (2001), that three groups of adolescents with a psychopathic personality can be distinguished: 1) adolescents scoring low on the manipulative, unemotional, and irresponsible dimension ('relatively normal group'), 2) adolescents scoring moderately on the manipulative and unemotional dimension and high on the irresponsible dimension ('impulsive, non-psychopathic-like group'), and 3) adolescents scoring high on all three dimensions ('psychopathy-like group'). Differences between the three subgroups were expected on externalizing problems, delinquent behavior, and substance use, with the psychopathy-like group showing more externalizing problems, delinquent behavior, and substance use compared to both other groups. It is also expected that higher psychopathic traits are related to more externalizing problems, delinquency and drugs use in boys as well as in girls. Concerning internalizing problems and psychopathic traits, the literature showed mixed findings, which makes it difficult to formulate hypotheses.

\section{Method}

Procedure and participants

Data for the current study were collected as part of a study examining the effects of a new residential treatment program for adolescents with severe behavior problems in the Netherlands. Four institutions participated in this study, all offering compulsory residential treatment to adolescents aged 12 to 18 . None of the adolescents entered the program due to convictions for criminal activities. Adolescents who entered this residential treatment between May 2007 and 
December 2008 were asked to complete a battery of questionnaires. Because the sample consisted of under aged adolescents with severe behavior problems, the research was reviewed and approved by the relevant medical ethics commission. The Dutch government demanded that these institutions participate in this study.

At time of admittance, both the parents as well as the adolescents were requested to sign a form in which they allowed us to use information for scientific purposes. Of all eligible participants, $65 \%(n=214)$ agreed to complete the baseline questionnaire. Across the participating institutions the response rates were $79 \%, 70 \%, 75 \%$ and $57 \%$ respectively. Of the $35 \%$ of adolescents who did not participate, in one case the parent did not allow her child to participate $(0.8 \%)$. The most important reason why adolescents did not participate reflected a lack of organizational structure in the institutions ( $96 \%$ of non-participating adolescents), such that adolescents admitted at the beginning of the new residential program were not given questionnaires to complete. Moreover, three adolescents (3\%) refused to participate, because they did not like to answer personal questions or because they were afraid that the information would be used against them. One adolescent was transferred shortly after admittance, so he was not able to fill in a questionnaire $(0.8 \%)$. Because the criteria for admittance were the same for all four institutions, there is no reason to assume that there is nonrandom attrition. The institutions sent the completed questionnaires back to the researchers. Each adolescent received five euros. Confidentiality was fully assured.
Of the 214 adolescents who participated in this study, the mean age of the adolescents was $15.76(\mathrm{SD}=1.29$, range $12-18$ ). For the boys, $50 \%$ had at least one parent born outside the Netherlands, whereas this was $46.8 \%$ for the girls (see Table 1). Table 1 also shows the means and standard deviations of problem behaviour, delinquency and drugs use of the adolescents. In addition, almost $70 \%$ of the adolescents showed both externalising as well as internalising problems. From Table 1 it appeared that girls showed significantly more internalizing problems than boys, for externalizing problems no gender differences were found. Boys showed higher scores on each of the three delinquency dimensions than girls. For drugs no gender differences were found.

\section{Measures}

Psychopathic traits The Dutch version of the Youth Psychopathic traits Inventory (YPI) was used to measure psychopathic traits (Andershed et al. 2001; Das and De Ruijter 2002). The YPI is a self-report measure consisting of 50 items measured on a 4-point Likert scale ranging from 1 (does not apply at all) to 4 (applies very well). These 50 items measure ten core traits of a psychopathic personality. Each of the 10 subscales consists of five items. The ten subscales are dishonest charm, grandiosity, lying, manipulation, callousness, unemotionality, remorselessness, impulsiveness, thrill seeking, and irresponsibility. The subscales are designed to reflect three dimensions: (1) a grandiose/manipulative dimension, (2) a callous/emotional

Table 1 Demographic information, means and standard deviations of problem behavior

\begin{tabular}{|c|c|c|c|c|c|}
\hline & \multicolumn{2}{|c|}{ Boys $(n=113)$} & \multicolumn{2}{|c|}{ Girls $(n=101)$} & \multirow[t]{2}{*}{$F$} \\
\hline & $M$ & $S D$ & $M$ & $S D$ & \\
\hline Age & 15.74 & 1.35 & 15.78 & 1.23 & 1.70 \\
\hline Ethnicity $^{\mathrm{a}}$ & $50.0 \%{ }^{\mathrm{a}}$ & & $46.8 \%{ }^{\mathrm{a}}$ & & 0.17 \\
\hline \multicolumn{6}{|l|}{ Problem behavior } \\
\hline Internalizing behavior & 10.32 & 8.67 & 16.16 & 11.13 & $9.71^{*}$ \\
\hline Externalizing behavior & 14.60 & 9.25 & 16.13 & 9.02 & 0.45 \\
\hline \multicolumn{6}{|l|}{ Delinquent behavior } \\
\hline Vandalism & 1.37 & 1.00 & 1.04 & 0.90 & $3.24 *$ \\
\hline Property offences & 1.00 & 1.04 & 0.59 & 0.62 & $24.53 * *$ \\
\hline Violent offences & 0.88 & 0.91 & 0.60 & 0.64 & $8.32 *$ \\
\hline \multicolumn{6}{|l|}{ Drug use } \\
\hline Soft drug & 3.65 & 2.12 & 3.68 & 2.02 & 1.52 \\
\hline Hard drug & 1.17 & 0.43 & 1.31 & 0.62 & 10.88 \\
\hline
\end{tabular}

${ }^{\text {a }}$ Etnicity was measured by the country of birth of the parents. The percentages reflect the youth having at least one parent born outside the Netherlands ${ }^{* *} p<0.01, * p<0.05$ 
dimension, and (3) an impulsive/irresponsible dimension. The first dimension measures the interpersonal aspects of a psychopathic personality, the second dimension assesses the affective aspects, and the third dimension describes the behavioral aspects. Internal consistencies of the subscales in the present study were similar to those reported in Andershed et al. (2001), ranging from 0.65 to 0.80 , with the exception of callousness (0.52). Prior studies found a good validity of the YPI (e.g., Andershed et al. 2007; Campbell et al. 2009; Hillege et al. 2010; Van Baardewijk et al. 2008).

Problem behavior The Youth Self Report (YSR; Achenbach 1991; Verhulst et al. 1997) was used to assess adolescents' problem behavior. All 112 items of the YSR are to be answered on a 3-point scale ranging from 0 (not at all) to 2 (often), with higher scores indicating more problems. The YSR consists of second order factors. The first second-order factor described as internalizing behavior consists of three factors, withdrawn behavior, somatic complaints, and anxious depressed behavior. The other second-order factor is externalizing behavior that consists of rule breaking and aggressive behavior. Cronbach's alpha in the present study for internalizing behavior was 0.93 and for externalizing behavior 0.90. According to Achenbach and Rescorla (2001) the validity of the YSR is good. The same was found for the Dutch version of the YSR (De Groot et al. 1996).

Delinquency A 26-item questionnaire consists of three subscales, property offenses (shoplifting), violent offenses (participating in a serious physical fight) and vandalism (damaging property), which assess delinquent behavior within the last year (see Van der Laan and Blom 2005). All items are measured on a 5 -point scale with 1 indicating 'never' $(0$ incidents), 2 'one incident', 3 'two incidents', 4 'three to ten,' and 5 'more than ten incidents.' Cronbach's alphas of the three subscales in the present study were 0.90 for property offenses (11 items), 0.80 for violent offenses ( 8 items), and 0.82 for vandalism ( 7 items). This delinquency self-report scale is considered to be valid (Van der Laan et al. 2006).

Drugs use To assess drugs use, adolescents self-reported the use of hash/marihuana, XTC, cocaine, magic mushrooms, uppers/pep/speed, or heroin within the last 12 months (Monshouwer et al. 2008; Van der Laan and Blom 2005). This variable was measured on a 6-point scale with 1 'never', 2 'seldom', 3 'couple of times a month', 4 'once a week', 5 'couple of times a week' to 6 'every day'. Hash and marihuana were classified as soft drugs, while XTC, cocaine, magic mushrooms, uppers, pep, speed and heroin were classified as hard drugs. Soft drugs and hard drugs were analyzed separately due to potentially different risk effects. Self-report measures concerning drugs use were found to be valid (O’Malley et al. 1983)
Statistical analyses

To test the dimensional factor structure of the ten subscales of the YPI in a referred sample, confirmatory factor analysis (CFA) was applied using Mplus 5.0 (Muthén and Muthén 1998-2006). The goodness of fit of the model was assessed using chi-square and the $p$-value, the Comparative Fit Index (CFI: Bentler 1989), and the Root Mean Square Error of Approximation (RMSEA: Steiger 1990). In this study, CFI values above 0.90 indicate an acceptable fit, and values above 0.95 indicate an excellent fit to the data, according to the generally accepted cutoff criteria of model fit indices. In addition, RMSEA values below 0.08 suggest an acceptable fit between the model and the data, and values below 0.05 indicate a good fit (Hu and Bentler 1999).

To test the relationships between the three factors of psychopathy and the dependent variables, Pearson correlations were calculated. Fisher's Z-tests for two correlations from independent samples (Cohen et al. 2003) were used to test differences between boys and girls in the correlations between the three factors and the dependent variables.

To identify different subgroups of adolescents with psychopathic traits, Latent Class Analyses (LCA; Muthén and Muthén 1998-2006) were performed using standardized scores (z-scores). Several criteria were used to support the optimal number of classes. The Bayesian Information Criterion (BIC; Schwarz 1978) with lower BIC-values indicating a better model fit was used to select the optimal model for these data. A second criterion was based on the classification quality of a model as determined by posterior probabilities. The latter expresses the degree to which participants belong to a specific class after the model is estimated. The higher these values the better the classification. A third criterion was based on the Likelihood Ratio Test (LRT). LRT tests whether a model with a $\mathrm{k}+1$ class solution is significantly better than a model with a k-class solution. Three slightly different LRTs are available in Mplus, the LOMendel-Rubin adjusted LRT, the Vuong-Lo-Mendel-Rubin LRT, and the parametric bootstrapped LRT. The results of the three LRTs are often comparable. The final criterion was the usefulness of the classes based on theoretical and/or practical considerations. The first three criteria may suggest a 4-class solution; however, if one of these classes contained a very small group with a mean that would not deviate significantly from one of the other three classes, a 3-class solution would be chosen, consistent with our theoretical expectations. After making a decision concerning the number of groups of adolescents with psychopathic traits, the Wald chi-square test of mean equality of potential latent class predictors (Asparouhouv and Muthén 2007) was performed, followed by post hoc tests, to test group differences in problem behavior, delinquent behavior, and substance use. With this test, the probabilistic nature of class 
membership is taken into account, leading to more unbiased mean estimates and their standard errors.

\section{Results}

\section{Confirmatory factor analysis (CFA)}

To verify the original factor model of Andershed et al. (2001), dishonest charm, lying, grandiosity, and manipulation subscales were included to describe the first factor called grandiose/manipulative. Remorselessness, unemotionality, and callousness subscales were included to describe the second factor denoted as callous/unemotional. Thrill seeking, impulsiveness, and irresponsibility subscales were included to describe the third factor defined as impulsive/irresponsible. CFA revealed that the 10 subscales adequately fitted the threefactor model, $\chi^{2}(d f=32, N=214)=103.34, p<0.001$, $\mathrm{CFI}=0.91$, RMSEA $=0.10$. However, the failure of the RMSEA to reach the usual cut-off must be viewed within the context of the CFA criteria possibly being overly restrictive. In line with Marsh et al. (2009) who noted that the usual cut-off scores of fit measures in CFA can be too restrictive as a consequence of constraining cross loadings to zero, we considered RSMEA-values of 0.10 acceptable. We conclude that the ten subscales fit the three-factor model moderately well. Moreover, other studies (Andershed et al. 2001; Hillege et al. 2010; Van Baardewijk et al. 2008) also used this three-factor model. The factor loadings of the 10 subscales varied between 0.41 and 0.91 (see Fig. 1). The internal consistencies of the three factors were $0.90,0.78$, and 0.86 , respectively. ${ }^{1}$

Correlations between YPI factors and the dependent variables

Gender differences indicated that the correlation between the grandiose/manipulative and the impulsive/irresponsible factor and internalizing problems were significantly higher for girls than for boys. For boys, however, the correlation between the callous/unemotional factor and externalizing problem behavior was higher than for girls. Also, both the grandiose/ manipulative and the callous/unemotional factor were higher correlated with drug use for boys than for girls (see Table 2).

\footnotetext{
${ }^{1}$ Gender was also included as a predictor of the latent variables in a so called MIMIC-model (Jöreskog and Goldberger 1975). Gender differences were only found for the callous/unemotional factor. The callousness indicator, on which boys scored higher compared to girls, seemed to influence the correlation. Is has to be kept in mind, however, that the sample size of the groups of boys and girls was rather small (girls $n=101$ and boys $n=113$ ); therefore, the results for boys and girls are not presented separately.
}

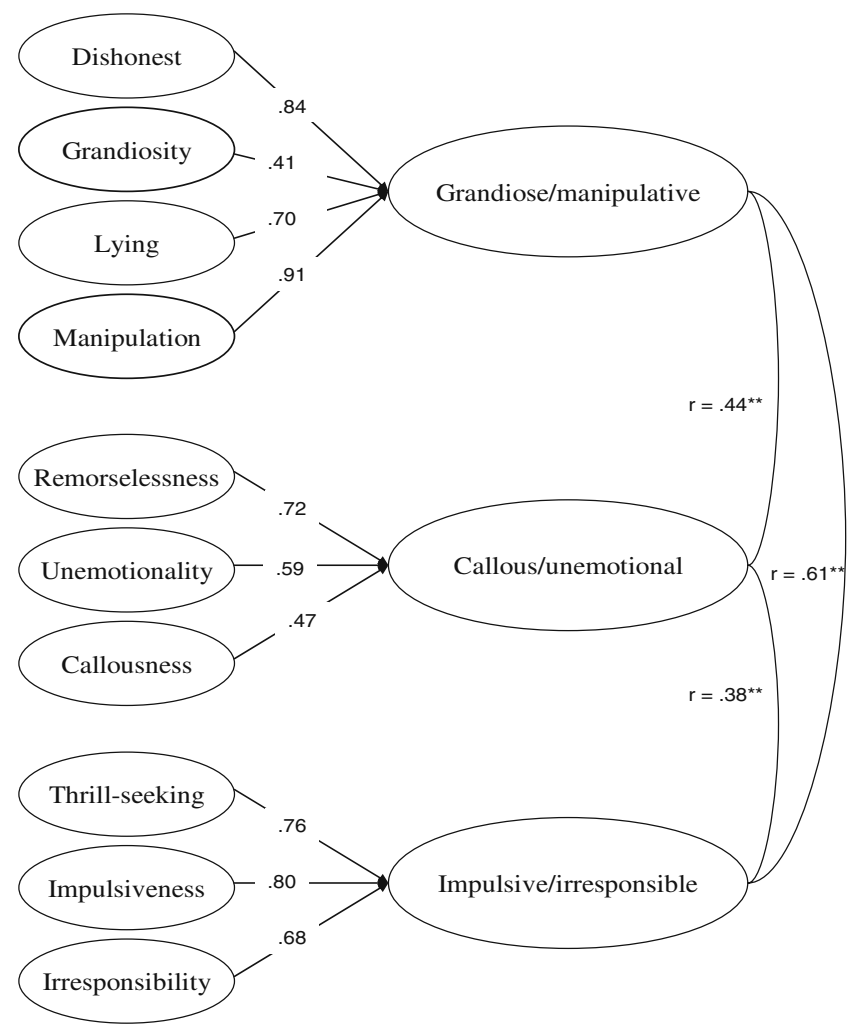

Fig. 1 Factor loadings and correlations between the subscales and the latent constructs of the YPI

\section{Latent Class Analyses (LCA)}

The three factor scores were entered into the LCA. Five models were estimated specifying the number of latent classes between one and five. The BIC-values were successively 1845 (1 class), 1723 (2 classes), 1678 (3 classes), 1671 (4 classes) and 1677 (5 classes). The biggest drop in BIC-value was from a one-class model to a two-class model (122) and from a two-class model to a three-class model (45). The drop from a three-class model to a four-class model was minor (7). A five-class model showed an increase (6). These results suggested that a three-class model or a four-class model were candidates for the final solution. The LRT indicated that a five-class model was not significantly better than a four-class model $(p>0.05)$. A four-class model was significantly better than a three-class model $(p<0.001)$, suggesting that a four-class model would be better than a three-class model. The classification quality of both models was good with posterior probabilities varying from 0.87 to 0.97 for the three-class solution and from 0.89 to 0.96 for the four-class solution. To make a final decision, we compared both models. The three-class model included one group of 110 adolescents with mean $\mathrm{z}$-scores (using $\mathrm{z}$-scores the mean is zero) of $-0.69,-0.41$, and -0.65 on grandiose/manipulative, callous/unemotional, and impulsive/irresponsible 
Table 2 Pearson correlations between the YPI factors, problem behavior, delinquent behavior and drug use

\begin{tabular}{|c|c|c|c|c|c|c|c|}
\hline YPI factors & INT & EXT & Vandalism & Property offences & Violent offences & Use of hard drug & Use of soft drug \\
\hline \multicolumn{8}{|l|}{ Boys $(n=113)$} \\
\hline Grandiose/manipulative & 0.01 & $0.58 * *$ & $0.37 * *$ & $0.39^{* *}$ & $0.47 * *$ & 0.13 & $0.42 * *$ \\
\hline Callous/unemotional & -0.05 & $\mathbf{0 . 5 3} * *$ & $0.33 * *$ & $0.31 * *$ & $0.46^{* *}$ & 0.06 & $0.35^{* *}$ \\
\hline Impulsive/irresponsible & $0.24 *$ & $0.78 * *$ & $0.57 * *$ & $0.54 * *$ & $0.54 * *$ & $0.32 * *$ & $0.45^{* *}$ \\
\hline \multicolumn{8}{|l|}{ Girls $(n=101)$} \\
\hline Grandiose/manipulative & $0.44 * *$ & $0.60 * *$ & $0.31 * *$ & $0.39 * *$ & $0.37 * *$ & 0.10 & 0.09 \\
\hline Callous/unemotional & 0.04 & $0.22 *$ & $0.24 *$ & 0.12 & 0.16 & $0.22 *$ & 0.01 \\
\hline Impulsive/irresponsible & $0.50 * *$ & $0.74 * *$ & $0.46^{* *}$ & $0.46^{* *}$ & $0.57 * *$ & $0.23 * *$ & $0.35 * *$ \\
\hline
\end{tabular}

$I N T$ internalizing problems, EXT externalizing problems, correlations that are bold were significantly different by gender

$* * p<0.01, * p<0.05$

dimensions respectively, one group of 82 adolescents with mean z-scores of $0.36,0.32$, and 0.64 on the same dimensions, and another group of 22 adolescents with mean $\mathrm{z}$-scores of $2.11,0.91$, and 1.05 on the same dimensions. The four-class model included one group of 109 adolescents with mean z-scores of $-0.69,-0.43$ and -0.68 on the grandiose/manipulative, callous/unemotional, and impulsive/irresponsible dimensions respectively, one group of 76 adolescents with mean z-scores of $0.30,0.35$ and 0.64 , one group of 22 adolescents with mean z-scores of 1.92, 0.26 and 0.70 and a final group of six adolescents with mean z-scores of $2.30,2.67$ and 1.97. Because the latter group was small, we decided to accept the three-class solution (see Fig. 2).

Considering the characteristics of these three subgroups, it seems that one subgroup in our sample scored low on all three dimensions measuring psychopathic traits. Another group had moderate to average scores on the first two dimensions but relatively high scores on the impulsive/ irresponsible dimension. Lastly, the third subgroup scored high on all three dimensions of psychopathic traits. We label these three groups, in accordance with Andershed et al. (2001), as a relatively normal group, an impulsive, non-psychopathic-like group, and a psychopathy-like group, respectively.

\section{Problem behavior}

Scores on the Youth Self Report (YSR) for the three psychopathy-like groups are presented in Table 3. For externalizing problem behavior it was found that the psychopathy-like group and the impulsive, non-psychopathic-like group differed from the normal group. The psychopathy-like and the impulsive, non-psychopathic-

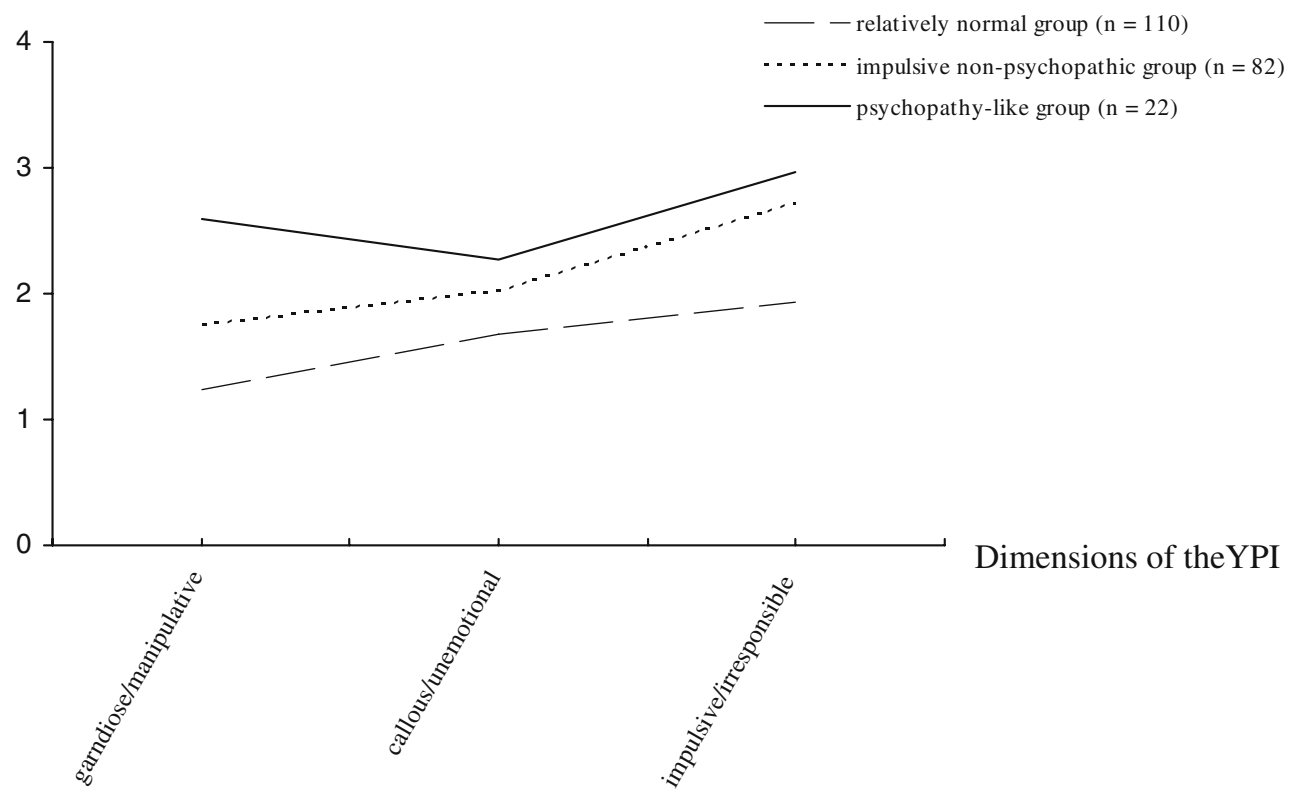

Fig. 2 Three subgroups of adolescents with psychopathic traits $(N=214)$ 
Table 3 Group differences on problem behavior, delinquency and drug use $(N=214)$

\begin{tabular}{|c|c|c|c|c|c|}
\hline & Normal & Impulsive & Psychopathy-like & $x^{2}$ & $p$ \\
\hline \multicolumn{6}{|l|}{ Problem behavior } \\
\hline Internalizing behavior & $10.32^{\mathrm{a}}$ & $17.11^{\mathrm{b}}$ & $12.85^{\mathrm{ab}}$ & 12.95 & 0.00 \\
\hline Externalizing behavior & $9.94^{\mathrm{a}}$ & $20.87^{\mathrm{b}}$ & $22.99^{\mathrm{b}}$ & 119.91 & 0.00 \\
\hline \multicolumn{6}{|l|}{ Delinquent behavior } \\
\hline Vandalism & $0.92^{\mathrm{a}}$ & $1.46^{\mathrm{b}}$ & $1.88^{\mathrm{b}}$ & 22.23 & 0.00 \\
\hline Property offences & $0.55^{\mathrm{a}}$ & $0.98^{\mathrm{b}}$ & $1.54^{\mathrm{c}}$ & 20.94 & 0.00 \\
\hline Violent offences & $0.47^{\mathrm{a}}$ & $0.92^{\mathrm{b}}$ & $1.52^{\mathrm{c}}$ & 27.06 & 0.00 \\
\hline \multicolumn{6}{|l|}{ Drug use } \\
\hline Soft drugs & $3.09^{\mathrm{a}}$ & $4.28^{\mathrm{b}}$ & $4.57^{\mathrm{b}}$ & 22.11 & 0.00 \\
\hline Hard drugs & 1.15 & 1.32 & 1.39 & 5.13 & 0.08 \\
\hline
\end{tabular}

Means with the different superscripts are significantly different from each other

like group scored significantly higher on externalizing behavior compared to the normal group. The psychopathylike group did not differ on internalizing behavior problems compared to the normal and the impulsive, non-psychopathic like group. However, the impulsive, non-psychopathic-like group showed higher scores on internalizing problems than the normal group (see Table 3).

\section{Delinquent behavior}

The normal group showed significantly less vandalism compared to the impulsive, non-psychopathic and psychopathy-like group. The impulsive, non-psychopathiclike group did not show less vandalism than the psychopathy-like group. Concerning property offences, the normal group showed less property offences compared to the impulsive, non-psychopathic and psychopathy-like group. The impulsive, non-psychopathic-like group scored lower than the psychopathy-like group. Looking at violent offences, the normal group committed fewer violent offences compared to the impulsive, non-psychopathic and psychopathy-like group. Again, the impulsive, nonpsychopathic-like group reported fewer violent offences compared to the psychopathy-like group (see Table 3).

\section{Substance use}

With respect to substance use, the impulsive, nonpsychopathic-like group and the psychopathy-like group used soft drugs more often compared to the normal group. No differences were found between the impulsive and psychopathy-like groups. Concerning the use of hard drugs, no statistical differences were found between the three subgroups (see Table 3).

\section{Discussion}

The present study examined the presence of psychopathic traits within a residential sample of adolescents and their relationship with problem behavior. Confirmatory Factor Analyses (CFA) showed that the variance of the YPI subscales could be explained by the three latent constructs, the grandiose/manipulative dimension (interpersonal), the callous/unemotional dimension (affective), and the impulsive/irresponsible dimension (behavioral), replicating the findings of Andershed et al. (2002). Poythress et al. (2006) also partly confirmed this finding. These authors found a satisfactory fit when the subscale lying was excluded and when the error terms for callousness and thrill seeking with unemotionality were correlated.

As hypothesized, three meaningful subgroups within the psychopathic personality could be distinguished. One subgroup of adolescents scored low on all three dimensions (normal group), one subgroup had moderate scores on the first two dimensions and relatively higher scores on the impulsive/irresponsible dimension (impulsive, nonpsychopathic-like group), and the third subgroup scored high on all three dimensions (psychopathy-like group).

In the next step, statistical differences between the three subgroups on problem behavior were tested, more specifically on internalizing behavior, externalizing behavior, delinquency, and drug use. Our findings showed, as expected, that the normal group showed significant lower levels of problem behavior compared to the impulsive, nonpsychopathic-like group and the psychopathy-like group. No differences between the impulsive, non-psychopathiclike and psychopathy-like group were found for externalizing and internalizing problem behavior.

As said earlier, an indirect relationship might be expected because internalizing problems are associated 
with externalizing problems, which have been found to be related to psychopathic traits. This suggests a correlation between internalizing problems and the behavioral factor of psychopathy. For boys the results indeed revealed a significant correlation between the behavioral factor and internalizing problems and not between the affective and interpersonal factors of psychopathy and internalizing problems. For girls, there was a significant correlation between the behavioral as well as the interpersonal factor of psychopathy and internalizing problems and no significant correlation between the affective factor and internalizing behavior problems. For boys only, these findings suggest that the link between psychopathic traits and internalizing problems is mediated by externalizing problems. For girls this indirect link is partially confirmed. However, these findings are not consistent with the findings of Sevecke et al. (2009b), who found an association between the affective factor and internalizing problems for boys. Possible explanations for this difference in results between the current study and the study of Sevecke et al. (2009b) can be found in the different samples; Sevecke et al. (2009b) included incarcerated adolescents, while the current study included adolescents admitted to residential care because they needed protection against themselves or their environment. It is also likely that the comorbidity rate between internalizing and externalizing problems in the current study $(67 \%)$ is higher than that in the Sevecke study of offenders. In this study we did not have longitudinal data and therefore our data did not allow the test of mediation. Further research should use longitudinal data to test a mediation model.

Other explanations for the different findings between Sevecke et al. (2009b) and the current study might include the different instruments used to measure psychopathic traits. Sevecke et al. (2009b) used the PCL: YV to measure psychopathic traits, while in this study the YPI was used. Based on previous studies showing only low to moderate correlations between the YPI and the PCL:YV, it is obvious that these two instruments do not measure exactly the same concept. Also the mean ages of the samples differed; the mean age of the sample used by Sevecke et al. (2009b) was 17.73 years of age for boys and 17.76 years of age for girls, while the mean age of the current study was 15.74 for boys and 15.78 for girls. Further research is needed to obtain a better insight into the associations between psychopathy and externalizing and internalizing problems, and possible moderation of these associations by age and gender.

Concerning delinquent behavior, our study found that the psychopathy-like group showed the highest levels of property and violent offences. Andershed et al. (2001) also found the highest delinquency rates among male adolescents scoring high on psychopathic traits. Furthermore, in the present study, both the impulsive, non-psychopathic-like and psychopathy-like group showed higher scores on drugs use compared to the normal group. Overall, our study showed that the psychopathy-like group did not substantially differ from the impulsive, non-psychopathic-like group.

It is sometimes suggested that individuals with psychopathic personality traits consist of two groups that can be differentiated based on genetic and environmental influences (Skeem et al. 2007). The 'primary psychopaths' have a genetic basis for their psychopathy while the 'secondary psychopaths' have an environmental basis. This distinction is based on the extent of anxiety, in which the primary psychopaths experience lower anxiety compared to the secondary psychopath. These authors also found that secondary psychopaths appeared to show behavior that is more withdrawn and emotionally more unstable compared to a non-psychopathic, violent control group. Based on this theory about subgroups of psychopaths, Wareham et al. (2009) examined subgroups of youth with psychopathic traits including indicators of anxiety. They found four subtypes, of which two types differed in the extent of anxiety, low versus high. The first subgroup is called the impulsive, non-psychopathic like group and the second group is called the impulsive-anxious group. The other two groups (the non-psychopathic group and the psychopathlike group) showed low levels of anxiety. Wareham et al. (2009) concluded that the psychopathy-like group reflects the primary psychopaths. Concerning the secondary psychopaths, they stated that it is more difficult to conclude which group they can be compared to, but individuals classified into the impulsive classes seem to have some characteristics of the secondary psychopaths. Looking at the indirect link between internalizing problems and psychopathic traits and the differences found between the study of Sevecke et al. (2009b) and our study, it might be possible that our sample reflect the secondary psychopaths showing especially reactive aggression and the study of Sevecke et al. reflect the primary psychopaths showing proactive aggression.

The strong association between psychopathic traits and externalizing behavior provides a solid foundation for future research and contributes to the existing literature (Forsman et al. 2007; Hart and Hare 1997; Lynam and Gudonis 2005). Our findings suggest that youth with psychopathic traits and youths showing impulsive behavior do not differ on externalizing problems. Consistent with the literature (e.g., Douglas et al. 2006; Forth et al. 2003; Hillege et al. 2010; Poythress et al. 2006), especially the impulsive/irresponsible dimension of psychopathy showed the strongest correlations with all measured problem behavior (internalizing, externalizing, substance use and delinquent behavior), which might explain the few differences found between both subgroups. This is also consistent with prior studies (Abramowitz et al. 2004; Colledge 
and Blair 2001; Mathias et al. 2007; Sevecke et al. 2009b), who found that externalizing problems are strongly related to the antisocial and behavioral dimensions of psychopathy. This suggests that the differences between the two groups are based on the interpersonal and affective dimensions of psychopathy. The support for the association between internalizing behavior and psychopathic traits is less straightforward. Prior studies (e.g. Brandt et al. 1997; Frick et al. 1999; Lambert et al. 2001; Lynam 1997; Poythress et al. 2006; Salekin et al. 2004) reported contradictive findings. Frick et al. (1999) stated that utilizing different measures or different concepts of a psychopathic personality (a single dimension versus separate dimensions) to test the relationships could explain the mixed findings in the literature.

\section{Limitations}

One of the shortcomings of the current study is that exclusively self-reports were used to examine psychopathic traits. Although self-reports can be seen as valid and reliable measures (Loeber et al. 1989), and some even say that they give a better insight into the subjective aspects of psychopathic traits (Andershed et al. 2002), still the risk of underreporting as a consequence of vulnerability to social desirability is present. Another shortcoming is that only $65 \%$ of the adolescents entering one of the participating institutions participated in the current study. The number and nature of the identified latent classes are specific to the sample used. Still, there were no indications that the drop out was not at random because the populations of the participating institutions did not differ from each other according to the later data assessments.

\section{Implications}

To our knowledge, most studies using the YPI to examine psychopathic traits are conducted on samples of male offenders, or normative samples. Our study extends these studies and overcomes this eminent shortcoming in this area of research by including males and females admitted to compulsory residential treatment. The findings of this study are consistent with previous findings, supporting the existence of the same three subgroups among different populations. Being able to distinguish subgroups within a residential sample showing severe problem behavior is important for prevention as well as intervention. Some scholars state that adolescents may benefit more from treatment because of their young age (Forth and Burke 1998). Our findings imply that the main treatment goals should be different based on the psychopathic traits of adolescents. For this reason, it is pivotal that further research includes follow-up data. One of the main questions then has to be whether the psychopathy-like group shows more negative outcomes in other areas, for example, living situation, school/work, contacts with the family, and behavior problems. Further research should also link core elements of this treatment to follow-up data as well as psychopathic traits. This would give more insight into the role of psychopathic traits as a moderator of treatment.

Open Access This article is distributed under the terms of the Creative Commons Attribution Noncommercial License which permits any noncommercial use, distribution, and reproduction in any medium, provided the original author(s) and source are credited.

\section{References}

Abramowitz, C. S., Kosson, D. S., \& Seidenberg, M. (2004). The relationship between childhood Attention Deficit Hyperactivity Disorder and conduct problems and adult psychopathy in male inmates. Personality and Individual Differences, 36, 10311047.

Achenbach, T. M. (1991). Manual for the child behavior checklist/418 and 1991 profile. Burlington: University of Vermont Department of Psychiatry.

Achenbach, T. M., \& Rescorla, L. A. (2001). Manual for the ASEBA school-age forms \& profiles. Burlington, VT: University of Vermont, Research Center for Children, Youth, \& Families.

American Psychiatric Association. (1994). Diagnostic and statistical manual of mental disorders (4th ed.). Washington DC: Author.

Andershed, H., Kerr, M., Stattin, H., \& Levander, S. (2001). Psychopathic traits in non-referred youth: A new assessment tool. In E. Blaauw, J. M. Philippa, K. C. M. P. Ferenschild, \& B. van Lodensteijn (Eds.), Psychopaths: Current international perspectives (pp. 131-158). The Hague: Elsevier.

Andershed, H., Gustafson, S. B., Kerr, M., \& Stattin, H. (2002). The usefulness of self-reported psychopathy-like traits in the study of antisocial behavior among non-referred adolescents. European Journal of Personality, 16, 383-402.

Andershed, H., Hodgins, S., \& Tengström, A. (2007). Convergent validity of the youth psychopathic traits inventory (YPI): association with the psychopathy checklist: youth version (PCL: YV). Assessment, 14, 144-154.

Andershed, H., Köhler, D., Louden, J. E., \& Hinrichs, G. (2008). Does the three-factor model of psychopathy identify a problematic subgroup of young offenders. International Journal of Law and Psychiatry, 31, 189-198.

Asparouhouv, T., \& Muthén, B. O. (2007). Wald test of mean equality for potential latent class predictors in mixture modeling. Retrieved November 9, 2009, from http://www.statmodel.com/ download/MeanTest1.pdf.

Barry, C. T., Frick, P. J., DeShazo, T. M., McCoy, M. G., Ellis, M., \& Loney, B. R. (2000). The importance of callous-unemotional traits for extending the concept of psychopathy to children. Journal of Abnormal Psychology, 109, 335-340.

Bentler, P. M. (1989). EQS: Structural equations program manual. Los Angeles: BMDP Statistical Software.

Blonigen, D. M., Carlson, S. R., Krueger, R. F., \& Patrick, C. J. (2003). A twin study of self-reported psychopathic personality traits. Personality and Individual Differences, 35, 179-197.

Bolt, D. M., Hare, R. D., Vitale, J. E., \& Newman, J. P. (2004). A multigroup item response theory analysis of the psychopathy checklist-revised. Psychological Assessment, 16, 155-168. 
Brandt, J. R., Kennedy, W. A., Patrick, C. J., \& Curtin, J. J. (1997). Assessment of psychopathy in a population of incarcerated adolescent offenders. Psychological Assessment, 9, 429-435.

Campbell, M. A., Doucette, N. L., \& French, S. (2009). Validity and stability of the youth psychopathic traits inventory in a nonforensic sample of young adults. Journal of Personality Assessment, 91, 584-592.

Cauffman, E., Kimonis, E. R., Dmitrieva, J., \& Monahan, K. C. (2009). A multi-method assessment of juvenile psychopathy: comparing the predictive utility of the PCL:YV, YPI and NEO PRI. Psychological Assessment, 21, 528-542.

Christian, R. E., Frick, P. J., Hill, N. L., Tyler, L., \& Frazer, D. R. (1997). Psychopathy and conduct problems in children: implications for subtyping children with conduct problems. Journal of the American Academy of Child and Adolescent Psychiatry, 36, 233-241.

Cohen, J., Cohen, P., West, S. G., \& Aiken, L. S. (2003). Applied multiple regression/correlation analysis for the behavioral sciences (3rd ed.). Mahwah: Lawrence Erlbaum Associates.

Colledge, E., \& Blair, R. J. R. (2001). The relationship in children between the inattention and impulsivity components of attention deficit and hyperactivity disorder and psychopathic tendencies. Personality and Individual Differences, 30, 1175-1187.

Das, J., \& de Ruijter, C. (2002). Nederlandse vertaling van de Youth Psychopathic traits Inventory [Dutch translation of the Youth Psychopathic traits Inventory]. Unpublished research version. Zutphen, The Netherlands: Adolescent Forensic Psychiatric Centre.

De Groot, A., Koot, H. M., \& Verhulst, F. C. (1996). Cross-cultural generelizability of the Youth Self Report and the Teacher's Report Form cross-informant syndromes. Journal of Abnormal Child Psychology, 24, 651-664.

Dolan, M., \& Rennie, C. (2006). Psychopathy checklist: Youth version and Youth Psychopathic trait Inventory: a comparison study. Personality and Individual Differences, 41, 779-789.

Douglas, K. S., Vincent, G. M., \& Edens, J. F. (2006). Risk for criminal recidivism: The role of psychopathy. In C. J. Patrick (Ed.), Handbook of psychopathy (pp. 533-554). New York: Guilford Press.

Edens, J. F., Campbell, J. S., \& Weir, J. M. (2007). Youth psychopathy and criminal recidivism: a meta-analysis of the psychopathy checklist measures. Law and Human Behavior, 31, 53-75.

Forsman, M., Larsson, H., Andershed, H., \& Lichtenstein, P. (2007). The association between persistent disruptive childhood behavior and the psychopathic personality constellation in adolescence: a twin study. British Journal of Developmental Psychology, 25, 383-398.

Forsman, M., Lichtenstein, P., Larsson, H., \& Andershed, H. (2008). Genetic effects explain the stability of psychopathic personality from mid- to late adolescence. Journal of Abnormal Psychology, 117, 606-617.

Forth, A. E., \& Burke, H. C. (1998). Psychopathy in adolescence: Assessment, violence, and developmental precursors. In D. J. Cooke, A. E. Forth, \& R. D. Hare (Eds.), Psychopathy: Theory, research, and implications for society (pp. 205-230). Dordrecht: Kluwer.

Forth, A. E., Kosson, D. S., \& Hare, R. D. (2003). Hare psychopathy checklist: Youth version. North Tonawanda: Multi-Health Systems.

Frick, P. J., Lilienfeld, S. O., Ellis, M. L., Loney, B. R., \& Silverthorn, P. (1999). The association between anxiety and psychopathy dimensions in children. Journal of Abnormal Child Psychology, 27, 381390.

Gustafson, S. B. (2000). Personality and organizational destructiveness: Fact, fiction and fable. In L. R. Bergman, R. B. Cairns, L. G. Nilsson, \& L. Nystedt (Eds.), Developmental science and the holistic approach (pp. 299-313). Mahwah: Erlbaum.

Hare, R. D. (1991). The Hare psychopathy checklist-revised: Manual. NY: North Tonawanda.
Hare, R. D. (2003). The Hare psychopathy checklist-revised (2nd ed.). Toronto: Multi-Health Systems. Multi-Health Systems, Inc.

Hart, S. D., \& Hare, R. D. (1997). The association between psychopathy and narcissism: Theoretical views and empirical evidence. In E. Ronningstam (Ed.), Disorders of narcissismtheoretical, empirical, and clinical implications (pp. 415-436). Washington: American Psychiatric Press.

Hillege, S., Das, J., \& De Ruiter, C. (2010). The Youth Psychopathic traits Inventory: psychometric properties and its relation to substance use and interpersonal style in a Dutch sample of nonreferred adolescents. Journal of Adolescence, 33, 83-91.

Hu, L., \& Bentler, P. M. (1999). Cut-off criteria for fit indices in covariance structure analysis: conventional criteria versus new alternatives. Structural Equation Modeling, 6, 1-55.

Johansson, P., Kerr, M., \& Andershed, H. (2005). Linking adult psychopathy with childhood hyperactivity-impulsivity-attention problems and conduct problems through retrospective selfreports. Journal of Personality Disorders, 19, 94-101.

Jöreskog, K. G., \& Goldberger, A. S. (1975). Estimation of a model with multiple indicators and multiple causes of a single latent variable. Journal of the American Statistical Association, 70, 631-639.

Kosson, D. S., Cyterski, T. D., Steuerwald, B. L., Neumann, C. S., \& Walker-Matthews, S. (2002). The reliability and validity of the psychopathy checklist: youth version in non-incarcerated males. Psychological Assessment, 14, 97-109.

Kubak, F. A., \& Salekin, R. T. (2009). Psychopathy and anxiety in children and adolescents: new insights on developmental pathways to offending. Journal of Psychopathology and Behavioral Assessment, 31, 271-284.

Lambert, E. W., Wahler, R. G., Andrade, A. R., \& Bickman, L. (2001). Looking for the disorder in conduct disorder. Journal of Abnormal Psychology, 110, 11-123.

Larsson, H., Lichtenstein, P., \& Andershed, H. (2006). A genetic factor explains most of the variation in the psychopathic personality. Journal of Abnormal Psychology, 115, 221-230.

Loeber, R., Stouthamer-Loeber, M., Van Kammen, W., \& Farrington, D. (1989). Development of a new measure for self-reported antisocial behavior in young children: Prevalence and reliability. In M. W. Klein (Ed.), Cross-sectional research in self-reported crime and delinquency (pp. 203-225). Dordrecht: Kluwer.

Loney, B. R., Frick, P. J., Clements, C. B., Ellis, M. L., \& Kerlin, K. (2003). Callous-unemotional traits, impulsivity, and emotional processing in antisocial adolescents. Journal of Clinical Child and Adolescent Psychology, 32, 66-80.

Loney, B. R., Taylor, J., Butler, M. A., \& Iacono, W. G. (2007). Adolescents' psychopathy features: 6-year temporal stability an the prediction of externalizing symptoms during the transition to adulthood. Aggressive Behavior, 33, 242-252.

Lynam, D. R. (1997). Childhood psychopathy: capturing the fledgling psychopath in a nomological net. Journal of Abnormal Psychology, $106,425-438$.

Lynam, D. R., \& Gudonis, L. (2005). The development of psychopathy. Annual Review of Clinical Psychology, 1, 381-407.

Lynam, D. R., Caspi, A., Moffitt, T. E., Loeber, R., \& StouthamerLoeber, M. (2007). Longitudinal evidence that psychopathy scores in early adolescence predict adult psychopathy. Journal of Abnormal Psychology, 116, 155-165.

Marsee, M. A., Silverthorn, P., \& Frick, P. J. (2005). The association of psychopathic traits with aggression and delinquency in non-referred boys and girls. Behavioral Sciences \& the Law, 23, 803-817.

Marsh, H. W., Muthén, B., Asparouhov, T., Lüdtke, O., Robitzsch, A., Morin, A. J. S., et al. (2009). Exploratory structural equation modeling, integrating CFA and EFA: application to students' evaluations of university teaching. Structural Equation Modeling, $16,439-476$. 
Mathias, C. W., Furr, R. M., Daniel, S. S., Marsh, D. M., Shannon, E. E., \& Dougherty, D. M. (2007). The relationship of inattentiveness, hyperactivity, and psychopathy among adolescents. Personality and Individual Differences, 43, 1333-1343.

Monshouwer, K., Verdurmen, J., Van Dorsselaer, S., Smit, E., Gorter, A., \& Vollebergh, W. (2008). Jeugd en riskant gedrag 2007: Kerngegevens uit het peilstationsonderzoek scholieren [Youth and risk behavior: Key figures from the school monitoring study]. Utrecht: Trimbos Instituut.

Murrie, D. C., \& Cornell, D. G. (2000). The millon adolescent clinical inventory and psychopathy. Journal of Personality Assessment, $75,110-125$.

Muthén, L.K., \& Muthén, B. O. (1998). MPLUS user's guide (4th ed.). Los Angeles, CA: Muthén \& Muthén.

Nijhof, K. S., Van Dam, C., Veerman, J. W., Engels, R. C. M. E., \& Scholte, R. (2010). Nieuw Zorgaanbod: Gesloten jeugdzorg voor adolescenten met ernstige gedragsproblemen [New Care: Compulsory youth care for adolescents with serious behavioral problems]. Pedagogiek, in press.

O'Malley, P., Bachman, J. G., \& Johnston, L. D. (1983). Reliability and consistency in self-reports of drug use. The International Journal of the Addictions, 18, 805-824.

Poythress, N. G., Dembo, R., Wareham, J., \& Greenbaum, P. E. (2006). Construct validity of the Youth Psychopathic traits Inventory (YPI) and the Antisocial Process Screening Device (APSD) with justice-involved adolescents. Criminal Justice and Behavior, 33, 26-55.

Russo, M. F., \& Beidel, D. C. (1993). Co-morbidity of childhood anxiety and externalizing disorders: prevalence, associated characteristics, and validation issues. Clinical Psychology Review, 14, 199-221.

Salekin, R. T. (2008). Psychopathy and recidivism from mid-adolescence to young adulthood: cumulating legal problems and limiting life opportunities. Journal of Abnormal Psychology, 117, 386-395.

Salekin, R. T., Rogers, R., \& Sewell, K. W. (1998). Construct validity of psychopathy in a female offender sample: a multitrait-multimethod evaluation. Journal of Abnormal Psychology, 106, 576-585.

Salekin, R. T., Leistico, A. R., Neumann, C. S., DiCicco, T. M., \& Duros, R. L. (2004). Psychopathy and comorbidity in a young offender sample: taking a closer look at psychopathy's potential importance over disruptive behavior disorders. Journal of Abnormal Psychology, 113, 416-427.

Schwarz, G. (1978). Estimating the dimension of a model. Annals of Statistics, 6, 461-464.

Sevecke, K., Kosson, D. S., \& Krischer, M. K. (2009a). The relationship between attention deficit hyperactivity disorder, conduct disorder, and psychopathy in adolescent male and female detainees. Behavioral Sciences \& the Law, 27, 577598.
Sevecke, K., Lehmkuhl, G., \& Krischer, M. K. (2009b). Examining relations between psychopathology and psychopathy dimensions among adolescent female and male offenders. European Child an Adolescent Psychiatry, 18, 85-95.

Skeem, J. L., \& Cauffman, E. (2003). Views of the downward extension: comparing the youth version of the Psychopathic Checklist with the Youth Psychopathic Traits Inventory. Behavioral Sciences \& the Law, 21, 737-770.

Skeem, J., Kerr, M., Johansson, P., Andershed, H., \& Louden, J. E. (2007). Two subtypes of psychopathic violent offenders that parallel primary and secondary variants. Journal of Abnormal Psychology, 116, 395-409.

Steiger, J. H. (1990). Structural model evaluation and modification: an interval estimation approach. Multivariate Behavioral Research, $25,173-180$.

Taylor, J., \& Lang, A. R. (2006). Psychopathy and substance use disorders. In C. J. Patrick (Ed.), Handbook of psychopathy (pp. 495-511). New York: Guilford Press.

Taylor, J., Loney, B. R., Bobadilla, L., Iacono, W. G., \& McGue, M. (2003). Genetic and environmental influences on psychopathy trait dimensions in a community sample of male twins. Journal of Abnormal Child Psychology, 31, 633-645.

Van Baardewijk, Y., Stegge, H., Andershed, H., Thomaes, S., Scholte, E., \& Vermeieren, R. (2008). Measuring psychopathic traits in children through self-report. The development of the Youth Psychopathic traits Inventory-Child Version. International Journal of Law and Psychiatry, 31, 199-209.

Van der Laan, A. M., \& Blom, M. (2005). WODC-Monitor zelfgerapporteerde jeugdcriminaliteit [WODC-Monitor selfreported youth criminality]. The Hague: WODC.

Van der Laan, A. M., Blom, M., Verwers, C., \& Essers, A. A. M. (2006). Jeugddelinquentie: risico's en bescherming: Bevindingen uit de WODC monitor Zelfgerapporteerde Jeugdcriminaliteit [Youth delinquency: Risks and protection: Findings from the WODC self-reported youth criminality]. The Hague: WODC.

Verhulst, F. C., Van der Ende, J., \& Koot, H. M. (1997). Handleiding voor de Youth Self-Report (YSR) [Manual for the Youth SelfReport (YSR)]. Rotterdam: Erasmus University.

Vincent, G. M., Vitacco, M. J., Grisso, T., \& Corrado, R. R. (2003). Subtypes of adolescent offenders: affective traits and antisocial behavior patterns. Behavioral Sciences \& the Law, 21, 695-712.

Walters, G. D. (2003). Predicting institutional adjustment and recidivism with the Psychopathy Checklist factor scores: a meta-analysis. Law and Human Behavior, 27, 541-558.

Wareham, J., Dembo, R., Poythress, N. G., Childs, K., \& Schmeidler, J. (2009). A latent class factor approach to identifying subtypes of juvenile diversion youths based on psychopathic features. Behavioral Sciences \& the Law, 27, 71-95. 